\title{
Penerapan Analytical Network Process Dalam Menentukan Ras Ayam Serama Simple Additive Weighting (SAW)
}

\author{
Wirhan Fahrozi ${ }^{1}$, Samsir ${ }^{2}$ \\ ${ }^{1}$ Universitas Potensi Utama, Medan, Indonesia \\ ${ }^{2}$ Universitas Al Washliyah Labuhanbatu, Rantauprapat, Indonesia
}

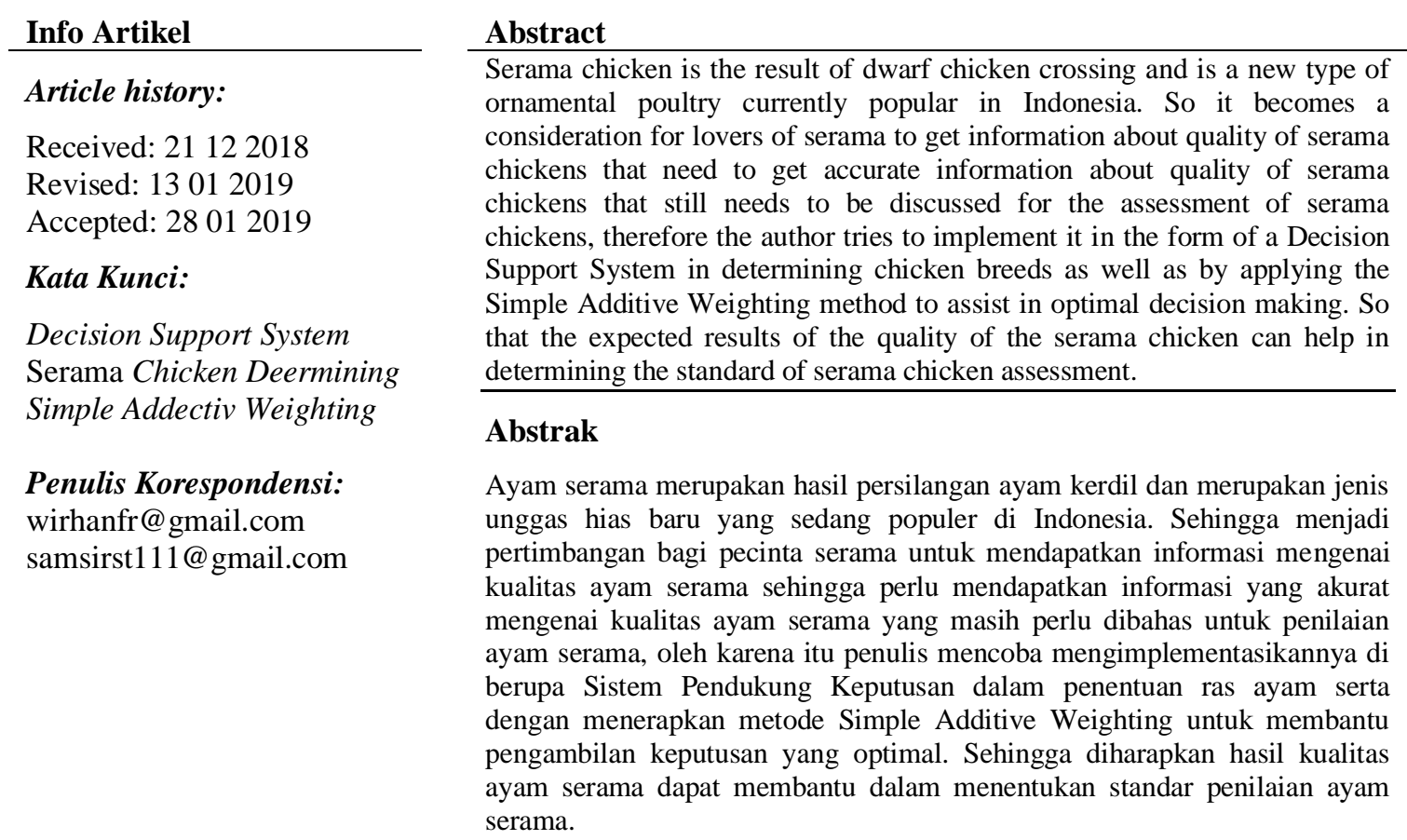

\section{PENDAHULUAN}

Ayam serama merupakan jenis unggas hias baru yang merupakan hasil persilangan yang dilakukan oleh seorang peternak asal klantan, bernama Mr.Wee Yean Ean. Mulanya, Mr Wee mencoba menyilangkan ayam katai kaki panjang biasa disebut ayam kapan dengan ayam ras Modern Game Bantam,[1] hasil persilangan tersebut dikawinkan dengan jenis ayam sutera(Silkie Bantams). Perkawinan ini menghasilkan ayam sutera berpostur kecil.Mr. Wee mencoba mengawinkan hasil dari percobaan kedua dengan ayam katai Jepang dan berhasil mencetak ayam mungil dengan bobot tubuh tidak lebih dari 500 gram. Hasil persilangan ini diberi nama serama.[2].

Sistem adalah kegiatan merancang detil dan rincian dari sistem yang akan dibuat sehingga sistem tersebut sesuai dengan requirement yang sudah ditetapkan dalam tahap analisa sistem.[3]

Subsistem manajemen data, subsistem manajemen model dan subsistem antarmuka pengguna. Selain itu DSS juga bisa memiliki subsistem manajemen basis-pengetahuan yang mengukung subsistemsubsistem lainnya.[4].Arsitektur aplikasi web meliputi klien, web server, middleware dan basis data. Klien berinteraksi dengan web server. Secara internal, web server berkomunikasi dengan middleware dan middleware yang berkomunikasi dengan basis data.[5] Contoh middleware adalah PHP dan ASP. Pada mekanisme aplikasi web dinamis, terjadi tambahan proses yaitu server menerjemahkan kode PHP menjadi kode HTML. Kode PHP yang diterjemahkan oleh mesin PHP yang akan diterima oleh klien.[6]. 


\section{KAJIAN LITERATUR}

\section{Pengertian Sistem Pengambil Keputusan}

Sistem pendukung keputusan tidak dimaksudkan untuk mengotomatisasikan pengambilan keputusan, tetapi, memberikan perangkat interaktif yang memungkinkan pengambil keputusan untuk melakukan berbagai analisis menggunakan model-model yang tersedia.[7]

Menurut Kusrini, M.Kom Sistem merupakan kumpulan elemen yang saling berkaian yang bertanggung jawab memproses masukan (input) sehingga menghasilkan keluaran (output).[8] Sistem pendukung keputusan adalah sistem penghasil informasi yang ditujukan pada suatu masalah tertentu yang harus dipecahkan oleh manager dan dapat membantu manager dalam pengambilan keputusan.[9] Sistem pendukung keputusan merupakan bagian tak terpisahkan dari totalitas sistem organisasi keseluruhan. [10]

\section{Pengertian Simple Addectiv Weighting}

Menurut Ardhi Bagus Primahudi (2016) Metode SAW sering juga dikenal istilah metode penjumlahan terbobot. Konsep dasar metode SAW adalah mencari penjumlahan terbobot dari rating kinerja pada setiap alternatif pada semua atribut. Metode SAW membutuhkan proses normalisasi matriks keputusan (X) ke suatu skala yang dapat diperbandingkan dengan semua rating alternatif yang ada.[11]

Metode Simple Additive Weighting sering juga di kenal dengan istilah metode penjumlahan berbobot. Konsep dasar metode Simple Additive Weighting adalah mencari penjumlahan terbobot dari rating kinerja pada setiap alternatif pada semua atribut.[12] Metode Simple Additive Weighting disarankan untuk menyelesaikan masalah penyeleksian dalam sistem pengambilan keputusan multi proses. Metode Simple Additive Weighting merupakan metode yang banyak digunakan dalam pengambilan keputusan yang memiliki banyak atribut. Metode Simple Additive Weighting membutuhkan proses normalisasi matriks keputusan (x) ke suatu skala yang dapat diperbandingkan dengan semua rating alternatif yang ada.[13] Formula untuk melakukan normalisasi tersebut adalah sebagai berikut:

$$
\mathrm{r}_{\mathrm{ij}}= \begin{cases}\frac{\mathrm{X}_{i j}}{\operatorname{Max} X_{i j}} & \text { jikaj attribut keuntungan (benefit) } \\ \frac{\operatorname{Min} X_{i j}}{X_{i j}} & \text { jikaj attribut biaya (cost) }\end{cases}
$$

Keterangan:

Max Xij = Nilai terbesar dari setiap kriteria i.

Min Xij = Nilai terkecil dari setiap kriteria i.

$\mathrm{Xij}=$ Nilai atribut yang dimiliki dari setiap kriteria.

Benefit $=$ Jika nilai terbesar adalah yang terbaik

Cost $=$ Jika nilai terkecil adalah yang terbaik.

Dimana rij adalah rating kinerja ternormalisasi dari alternatif Ai pada atribut $\mathrm{Cij} i=1,2, \ldots, n$. Nilai preferensi untuk setiap alternatif ( $\mathrm{Vi})$ di berikan sebagai:

$$
V_{i}=\sum_{j=1}^{n} w_{j} r_{i j}
$$

Keterangan:

$\mathrm{Vi}=$ Rangking untuk setiap alternatif.

$\mathrm{Wj}=$ Nilai bobot rangking (dari setiap kriteria).

rij = Nilai rating kinerja ternormalisasi.

Nilai Vi yang lebih besar mengidentifikasikan bahwa alternatif Ai lebih terpilih. Langkah Penyelesaian Metode SAW Dalam penelitian ini menggunakan FMDAM metode SAW. Langkah-langkah pemecahan masalah dalam penelitian ini adalah sebagai berikut: 
1. Menentukan kriteria-kriteria yang akan dijadikan acuan dalam menentukan pengambilan keputusan $\mathrm{Cj}$.

2. Memberikan nilai setiap alternatif (Ai) pada setiap kriteria (Cj) yang sudah ditentukan, dimana nilai $\mathrm{i}=1,2, \ldots \ldots \mathrm{n}$.

3. Menentukan rating kecocokan setiap alternatif pada setiap kriteria kemudian memodelkannya ke dalam bilangan fuzzy setelah itu dikonversikan kebilangan crisp.

4. Memberikan nilai bobot (W) yang juga didapatkan berdasarkan nilai crisp.

5. Melakukan normalisasi matriks dengan cara menghitung nilai rating kinerja ternormalisasi (rij) dari alternatif $\mathrm{Ai}$ pada atribut $\mathrm{Cj}$ berdasarkan persamaan yang disesuaikan dengan jenis atribut(atribut keuntungan/benefit $=$ MAXIMUM atau atribut biaya/cost $=$ MINIMUM). Apabila berupa atribut keuntungan maka crisp (Xi j) dari setiap kolom atribut dibagi dengan nilai crisp MAX (MAX Xi j) dari setiap kolom, sedangkan untuk atribut biaya, nilai crisp MIN (MIN Xi j) dari setiap kolom atribut dibagi dengan nilai crisp (Xi j) setiap kolom.

6. Melakukan proses perangkingan untuk setiap alternatif (Vi) dengan cara mengalikan nilai (Wi) dengan nilai rating kinerja ternormalisasi (rij).

Menentukan nilai prefensi untuk setiap alternatif (Vi) dengan cara menjumlahkan hasil kali antara matriks ternormalisasi $(\mathrm{R})$ dengan nilai bobot (W). Nilai Vi yang lebih besar mengindikasikan bahwa alternatif Ai. Frieyadie (2016:38-39).

\section{Analisa}

Sebagai langkah awal yang dilakukan supaya dapat mengetahui gambaran permasalahan yang dihadapi dalam menentukan rasa yam serama adalah dengan melakukan analisis permasalahan (problem analysis). Dengan melakukan analysis permasalahan diharapkan dapat memberikan solusi sesuai permasalahan yang dihadapi.[14] Permasalahan yang sering dihadapi dalam menentukan rasa yam serama adalah Pada bentuk tubuh meliputi assesoris yang dimiliki postur tubuh, usia/umur, trah/silsilah keturunan, dan jenis kelamin.[15]

\section{Perancangan}

Tahap pembuatan aplikasi ini, terlebih dahulu adalah menentukan dan merencanakan kriteria-kriteria dalam menentukan rasa yam serama. Dalam penelitian ini ada bobot dan kriteria yang dibutuhkan untuk menentukan ayam yang memiliki ras serama asli.

\section{Implementasi}

Pada pembahasan menu utama ini berisitentang halaman utama, yang mana dilengkapi beberapa menu-menu untuk kelanjutannya, dari gambaran diatas maka penulis akan memperlihatkan gambaran seperti dibawah ini 1. Form Login

\section{Gambar 1. Form Login}

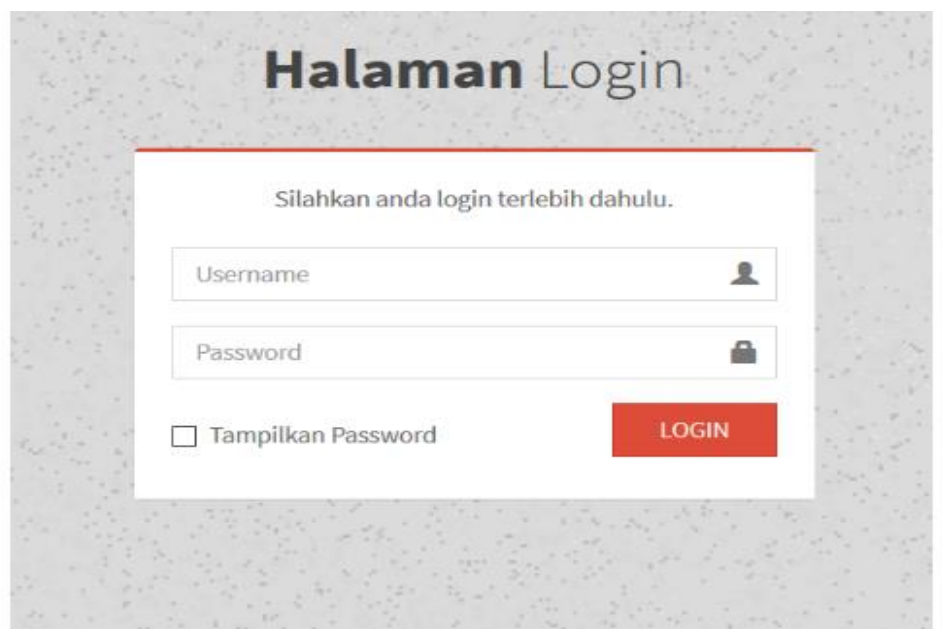

U-NET Jurnal Teknik Informatika, Vol. 03, No. 01, Februari 2019: 28 - 34 
Menu ini untuk admin dan user konsultasi yang akan login, seperti pada Gambar 1. dibawah ini : 2. Beranda Admin

Halama utama admin terdapat beberapa aktifasi yang dimilikinya seperti data user(admin dan user konsultasi) konsultasi berupa data ayam serama dan ayam serama itu sendiri beserta perhitungan SAW dalam menentukan ras ayam serama

\section{Gambar 2. Halaman Beranda Admin}

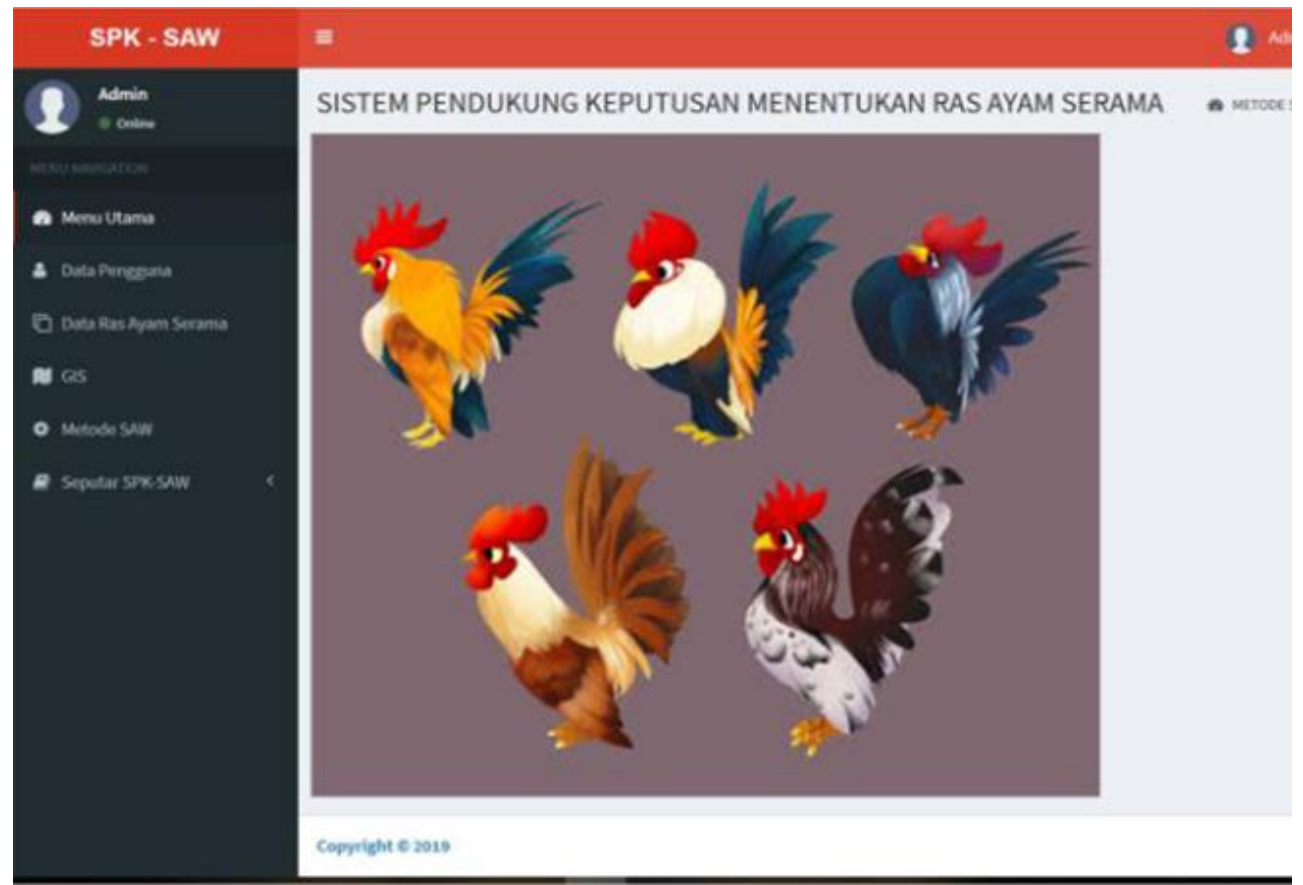

3. Menu Alternatif/Ayam serama

Sedangkan menu ini untuk melihat informasi tentang alternative/ayam serama, seperti pada Gambar 3. dibawah ini :

\section{Gambar 3. Menu tampilan informasi ras ayam serama}

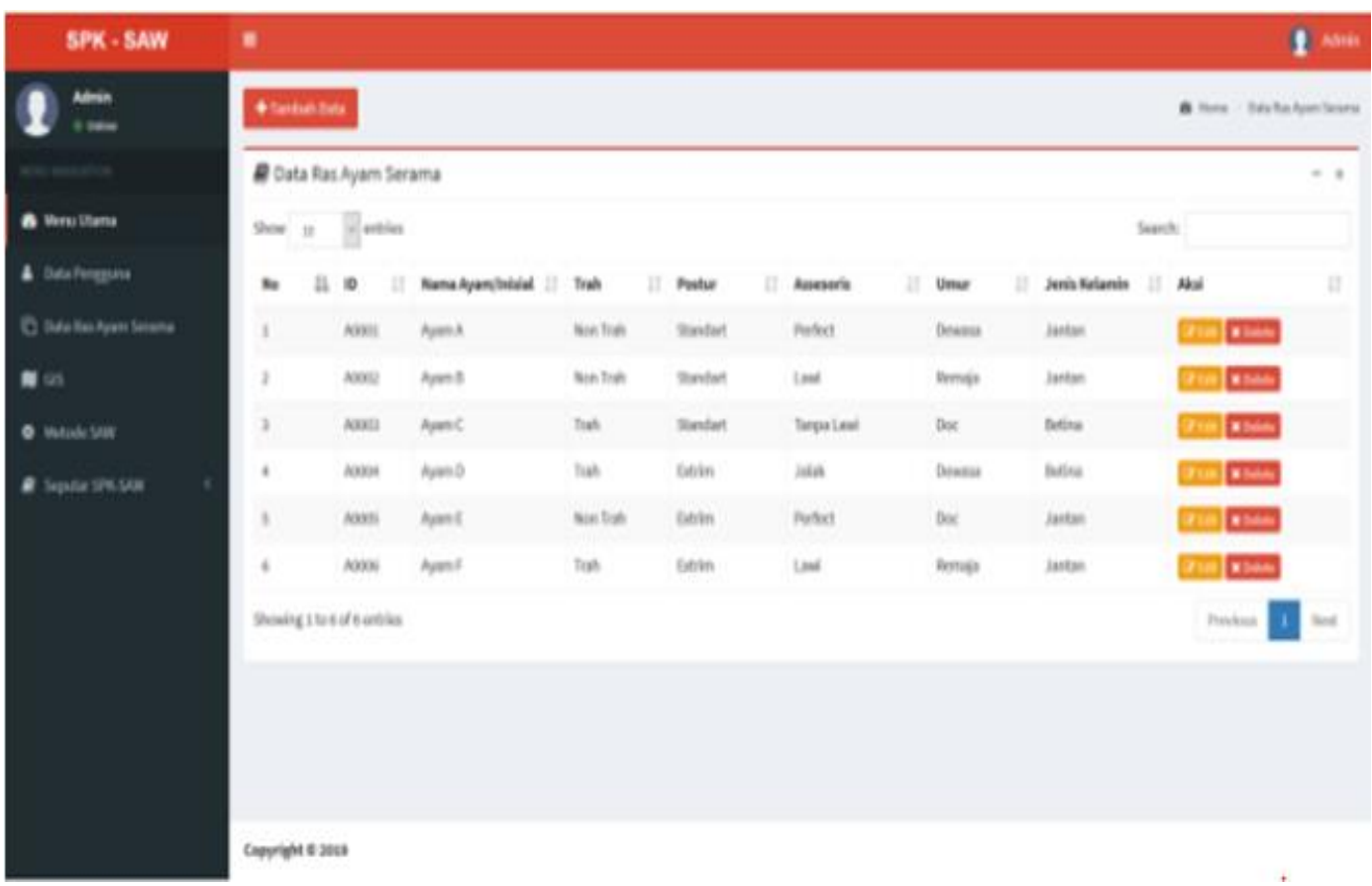


4. Beranda User

Halaman data user meliputi aktivasi input, edit dan hapus admin terhadap data user admin dan konsultasi.

Gambar 4. Menu Data User

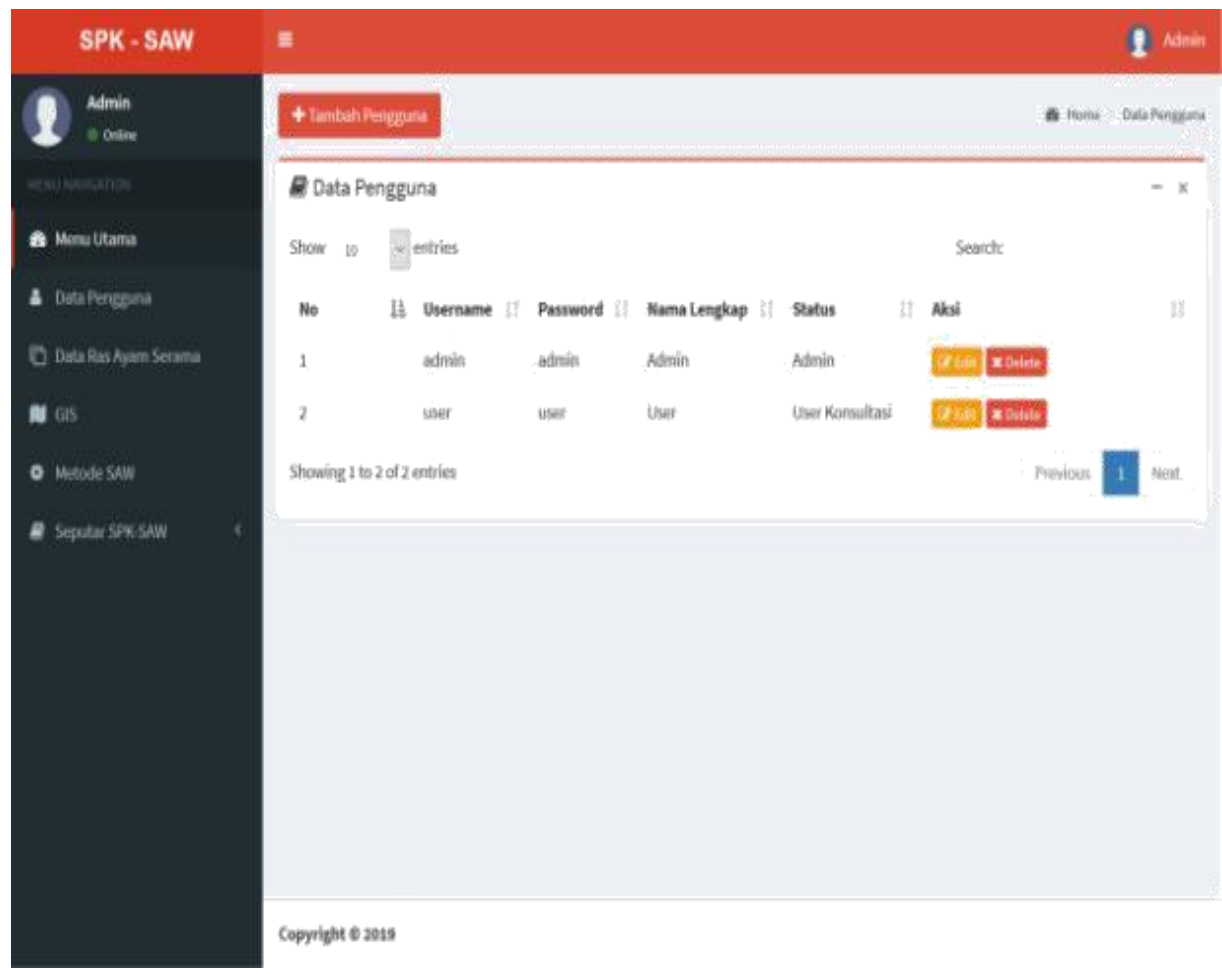

5. Beranda Perhitungan SAW

Halaman data admin hasil konsultasi user.

Gambar 5. Menu Perhitungan SAW

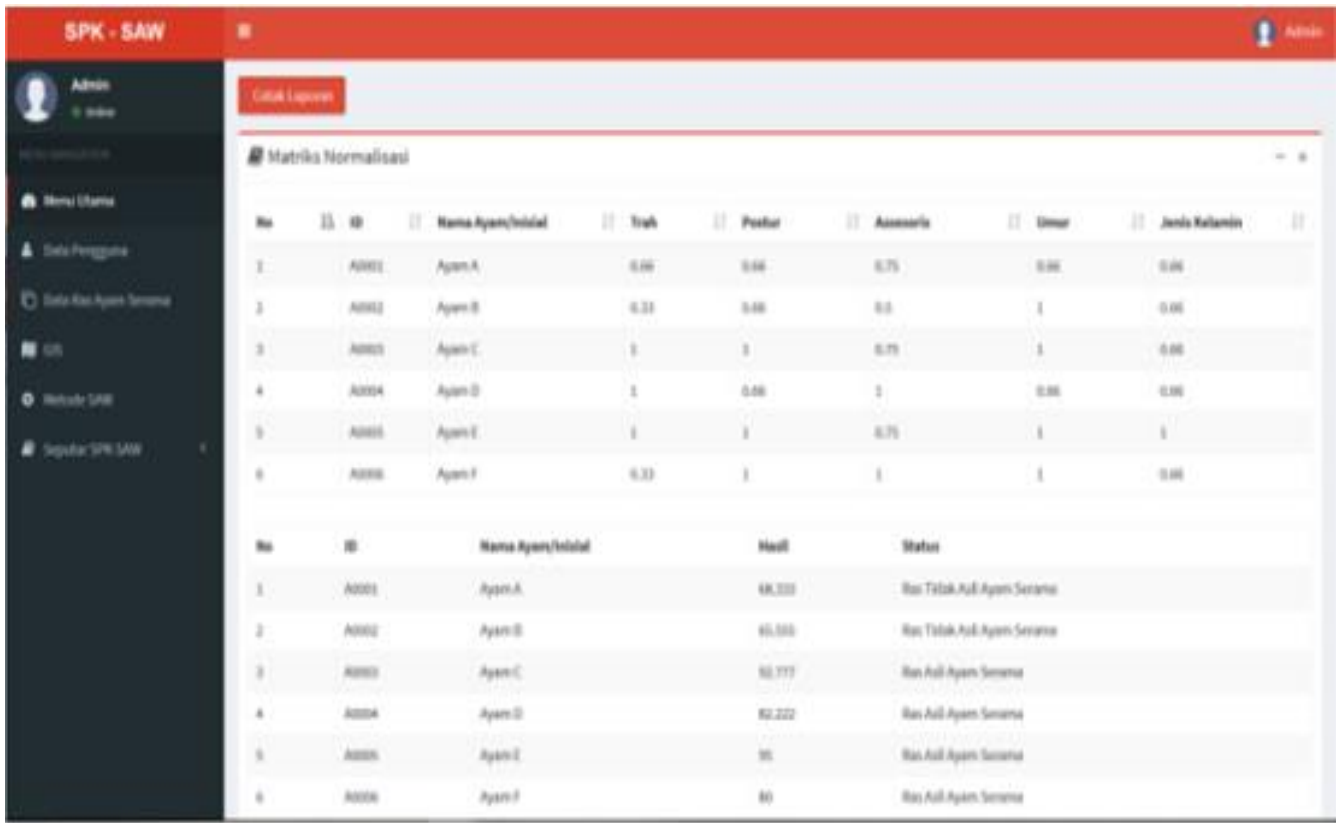


6. Laporan

Halaman laporan hasil konsultasi user konsultasi

Gambar 6. Laporan Konsultasi

\begin{tabular}{|c|c|c|c|c|}
\hline No & Kode & Nama Ayam/nisial & Hasil & Status \\
\hline 1 & AO0O1 & AyamA & 68.333 & Ras Tidak Asil Ayam Serama \\
\hline 2 & A0002 & Ayam B & 65.555 & Ras Tidak Asil Ayam Serama \\
\hline 3 & A0003 & AyamC & 92.777 & Ras Asi Ayam Serama \\
\hline 4 & $\mathrm{AOOOS}$ & Ayam D & 82222 & Ras Asil Ayam Serama \\
\hline 5 & A0005 & Ayam E & 95 & Ras Asi Ayam Serama \\
\hline 6 & A0006 & AyamF & 80 & Ras Asi Ayam Serama \\
\hline
\end{tabular}

\section{Kesimpulan}

Dari hasil analisa sistem pendukung keputusan pada dalam menetapkan ras ayam serama dengan menggunakan metode SAW, dapat disimpulkan bahwa :

1. Sistem Pendukung Keputusan yang dibuat dengan menggunakan metode SAW dapat melakukan perhitungan secara otomatis ketika pengguna menginputkan nilai dan bobot, sehingga dapat mengurangi masalah dalam pengambilan keputusan dalam penetapan ras ayam serama.

2. Adapun kriteria-kriteria yang diambil dalam sistem pendukung keputusan ini mengacu pada pedoman standarisasi penilaian ayam serama Indonesia.

3. Software super decisions telah dapat memenuhi kebutuhan untuk membantu dalam penentapan rasa ayam serama yang paling sesuai dengan kriteria-kriteria yang telah ditentukan oleh pihak standarisasi penilaian ayam serama Indonesia. 


\section{REFERENSI}

[1] F. Edi, P. T. Informatika, and F. U. A. Labuhanbatu, "UNET | Jurnal Ilmiah Teknik Informatika LPPM Universitas Al Washliyah Labuhanbatu UNET | Jurnal Ilmiah Teknik Informatika ISSN . 2460-3694, Vol . 2 No . 1 Februari 2018," vol. 2, no. 1, pp. 2-5, 2018.

[2] D. I. G. H. Wirhan Fahrozi, Samsir, "Penerapan E-Commerce Pada Toko Bunga Underwear," J. Tek. Inform., vol. 04, no. 01, pp. 1-6, 2020.

[3] S. Samsir, S. Suparno, and M. Giatman, "Predicting the loan risk towards new customer applying data mining using nearest neighbor algorithm," IOP Conf. Ser. Mater. Sci. Eng., vol. 830, no. 3, 2020, doi: 10.1088/1757-899X/830/3/032004.

[4] R. A. Purba, S. Samsir, M. Siddik, S. Sondang, and M. F. Nasir, "The optimalization of backpropagation neural networks to simplify decision making," IOP Conf. Ser. Mater. Sci. Eng., vol. 830, no. 2, 2020, doi: 10.1088/1757-899X/830/2/022091.

[5] Samsir, "Klasifikasi Penyakit Tenggorokan Hidung Telinga ( THT ) Menggunakan Jaringan Syaraf Tiruan Dengan Metode Learning Vektor Quantization ( THT ) Di RSUD Rantauprapat Labuhanbatu Klasifikasi penyakit Tenggorokan Hidung Telinga ( THT ) Menggunakan,” vol. 05, no. 01, pp. 3847, 2019.

[6] D. Indra et al., "SPK Untuk Pemilihan Kepala Sekolah Menggunakan Metode Saw dan Profile Matching," vol. 4, no. 1, pp. 7-12, 2020.

[7] P. T. Informatika and F. U. A. Labuhanbatu, "U-NET : Jurnal Teknik Informatika LPPM Universitas Al Washliyah Labuhanbatu 18 | P a g e U-NET : Jurnal Teknik Informatika Sebagai langkah awal yang dilakukan supaya dapat mengetahui gambaran permasalahan yang dihadapi oleh bagian kesiswaan adalah denga," vol. 3, no. 4, pp. 18-22, 2019.

[8] M. Siddik and S. Samsir, "Rancang Bangun Sistem Informasi Pos (Point of Sale) Untuk Kasir Menggunakan Konsep Bahasa Pemrograman Orientasi Objek," JOISIE (Journal Inf. Syst. Informatics Eng., vol. 4, no. 1, p. 43, 2020, doi: 10.35145/joisie.v4i1.607.

[9] Samsir and Syaiful Zuhri Harahap, "Application Design Resume Medical By Using Microsoft Visual Basic. Net 2010 At the Health Center Appointments,” Int. J. Sci. Technol. Manag., vol. 1, no. 1, pp. 14-20, 2020, doi: 10.46729/ijstm.v1i1.5.

[10] M. V. B. Net, "PADA TOKO URIP MOTOR,” no. September, pp. 1-6, 2020.

[11] Samsir, D. I. G. Hts, and S. Z. Harahap, "SPK Untuk Pemilihan Kepala Sekolah Menggunakan Metode Saw dan Profile Matching," U-NET J. Tek. Inform., 2020.

[12] J. H. P. Sitorus et al., "Perancangan pengontrol lampu rumah miniatur dengan menggunakan micro controler arduino berbasis android 1," vol. 4, no. 1, pp. 1-11, 2020.

[13] U. Verawardina, F. Edi, and R. Watrianthos, "Analisis Sentimen Pembelajaran Daring Pada Twitter di Masa Pandemi COVID-19 Menggunakan Metode Naïve Bayes,” vol. 5, pp. 157-163, 2021, doi: 10.30865/mib.v5i1.2604.

[14] S. Zulkifli, "Implementasi Sistem Keamanan SQL Injection Dalam berbasis web," Ejurnal.Univalabuhanbatu.Ac.Id, vol. 04, no. 01, pp. 13-17, 2020, [Online]. Available: https://ejurnal.univalabuhanbatu.ac.id/index.php/u-net/article/download/164/130.

[15] Syaiful Zuhri Harahap and Samsir, "Application Design The Data Collection Features of The Hotel Shades of Rantauprapat Using VBNET," Int. J. Sci. Technol. Manag., 2020, doi: 10.46729/ijstm.v1i1.4. 